C O L A B O R A Ç Ã O E S P E C I A L

\title{
ESQUECIMENTO E HISTORICIZAÇÃO DA MEMÓRIA
}

\author{
Oblivion and historicization of memory
}

HERMANN LÜBBE

http://dx.doi.org/10.1590/S0103-21862016000100015

Hermann Lübbe é professor emérito de Filosofia e Teoria Política do Departamento de Filosofia da Universidade de Zurique (hermann.luebbe@access.uzh.ch).

Uma versão abreviada deste artigo foi apresentada no simpósio "Culturas da ruptura", realizado entre 28 e 30 de junho de 2012 na Haus der Berliner Festspiele, e posteriormente publicada na revista da Kuturstiftung des Bundes, n. 20, primeiro semestre de 2013, p. 36-39. A versão definitiva, aqui traduzida, foi publicada no livro mais recente do autor (Lübbe, 2014: 281-298). 0 tradutor Sérgio da Mata gostaria de expressar sua gratidão a Hermann Lübbe pela autorização para a publicação de seu texto, assim como aos editores de Estudos Históricos pelo pronto interesse em dar a público esta primeira tradução de um ensaio de Lübbe em língua portuguesa. 


\title{
ResUmo
}

Este ensaio discute alguns aspectos da dialética que se desenvolve entre memória e esquecimento nas sociedades contemporâneas. Descreve como esta complexa relação se apresenta em distintos espaços institucionais e culturais, tais como museus, arquivos públicos e políticas da memória, justamente numa época que se coloca sob o signo da inovação. Ao menos três questões emergem de uma fenomenologia da consciência histórica atual: nossas sociedades de fato sofrem de um excesso de história? Há limites para os usos do passado? A fim de explicar adequadamente nossa situação civilizacional deveríamos adotar um conceito mais amplo de história?

PalaVras-CHAVE: aceleração civilizacional; consciência histórica; explicação histórica.

\begin{abstract}
This essay addresses the dialectical relationship between memory and oblivion that is characteristic of contemporary societies. It describes how this complex relationship presents itself in different institutional and cultural settings, such as museums, public archives, and politics of memory, pointing to its central place in a time that unfolds under the banner of innovation. Such a phenomenology of the modern historical consciousness raises at least three main questions: do our societies really suffer from an excess of history? Are there limits to the practical use of the past? Should we resort to a broader concept of history in order to better explain our own civilizational situation?
\end{abstract}

KeYwORDs: civilizational acceleration; historical consciousness; historical explanation.

\section{RÉSUMÉ}

Cet article discute quelques aspects de la dialectique qui s'établit entre mémoire et oubli dans les societés contemporaines. II décrit comment ce rapport complexe se présente dans les différents espaces institutionnels, tels que musées, archives publics et politiques de mémoire, dans une époque qui se place sous le signe de I'innovation. Trois questions au moins émergent d'une fénomenologie de la conscience historique actuelle: nos sociétés souffrent en effet d'un excès d'histoire? Y a-t-il des limites pour l'usage du passé? À fin d'expliquer correctement notre situation civilisationnelle devrions nous adopter un concept plus ample d' histoire?

Mots-CLÉS: accelération civilisationnelle; conscience historique; explication historique. 


\section{O ESQUECIMENTO NA FILOSOFIA MORAL E NA CRÍTICA OBSOLETA DE FRIEDRICH NIETZSCHE AO HISTORISMO}

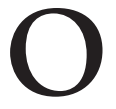

esquecimento, como se sabe, é um tema rico de tradições no pensamento moral europeu. Espontaneamente nos ocorrem algumas regras conhecidas que se destinam a evitar o esquecimento potencialmente prejudicial e, de forma complementar, a garantir a confiabilidade da memória. Na década de 1990 Harald Weinrich (2001) nos lembrou, em seu brilhante livro Lete, que existe um lado totalmente diferente na filosofia moral do esquecimento, qual seja: a forma como lidamos com nossa dependência do esquecimento e, portanto, com a existência de uma teoria que nos permite evitar lembranças perturbadoras e, enfim, esquecê-las. A fim de esclarecer essa teoria do esquecimento, evoco uma regra única e trivial sem a qual seria impossível um uso produtivo do tempo - na vida cotidiana de qualquer pessoa e inclusive na mesa de trabalho dos eruditos. A regra comum a que me refiro é a que permite conciliar mesmo 0 inevitável dever de memória com o alívio psíquico produzido pelo esquecimento. Como dizem os burocratas, estabelece-se um "prazo" de interdição para o acesso às coisas que não devem ser esquecidas, o que nos libera, no presente, da perturbadora memória que produzem.

Tal regra, que garante o alívio psíquico do dever de lembrança em favor de períodos de tranquilo esquecimento, é, como eu já disse, trivial. Mas é precisamente com essas trivialidades que o conhecimento moral tradicionalmente se relaciona - a saber, com os princípios elementares aos quais estamos sempre e por toda parte submetidos. Certamente existem estilos de vida que se levantam contra isso, e sua moral ainda mais rigorosa é parte da nossa cultura intelectual. Como nenhum outro, Friedrich Nietzsche argumentou que o esquecimento é uma necessidade existencial. "Em meio à menor como em meio à maior felicidade é sempre uma única coisa que torna a felicidade o que ela é: o poder-esquecer" (Nietzsche, 2003: 9). Deixemos de lado aqui a boa intenção que há por trás dessa rica tradição que associa a felicidade ao esquecimento. Só mencionei a doutrina do esquecimento de Nietzsche para enfatizar a sua radicalização no âmbito da crítica da modernidade. É sabido que Nietzsche articulou sua filosofia do esquecimento a uma crítica cultural do historismo (Historismus) moderno. ${ }^{1} 0$ esquecimento enquanto caminho para a felicidade - isso seria "a faculdade de sentir a-historicamente durante a sua duração" (Nietzsche, 2003: 9). Seria exatamente esta capacidade que a moderna cultura da memória, organizada e cientificizada, estaria arruinando - com seu nível sem precedentes "de insônia, de ruminação, de sentido histórico, no qual o vivente se degrada e por fim sucumbe, seja ele um homem, um povo ou uma cultura" (Nietzsche, 2003: 10). A quintessência da crítica cultural anti-historista de Nietzsche é "que padecemos todos de uma ardente febre histórica e ao menos deveríamos reconhecer que padecemos dela" (Nietzsche, 2003: 6). 
Para se ter uma ideia das consequências supostamente destrutivas do historismo denunciadas por Nietzsche, pode-se evocar o caso do historismo arquitetônico. Em suas Considerações intempestivas, Nietzsche afirmou que a "cultura" seria "acima de tudo a unidade do estilo artístico em todas as expressões da vida" (Nietzsche, 1980: 163). Avaliado a partir deste conceito normativo de cultura, a decadência de um ambiente urbanístico seria irreversível caso nele se encontrem uma igreja em estilo neogótico, uma escola secundária num culto estilo renascentista, um banco num pesado neobarroco e, por fim, uma estação de correios feita de tijolos em estilo gótico. Com efeito: da perspectiva da história da arquitetura o historismo arquitetônico logo foi superado - e, de forma radical, no âmbito da Bauhaus.

Nesse meio tempo, a própria Bauhaus foi historicizada, imitada de maneira ainda mais efêmera e, com suas citações histórico-arquitetônicas, finalmente refutada na pós-modernidade (Klotz, 1987). Some-se a isso o fato de que, e para além da Bauhaus, o próprio historismo arquitetônico tornou-se um objeto de preservação patrimonial. ${ }^{2} \mathrm{~A}$ "febre histórica" , tão criticada por Nietzsche, é produtiva e não "destrutiva" (cf. Lübbe, 2004a: 114-128). A resposta à questão colocada por Nietzsche, de se considerar o historismo como um "preconceito ocidental" (Nietzsche, 2003: 16) e ainda enquanto meio de desvitalização cultural, deveria ser deixada aqui a cargo dos estudos nietzschianos. ${ }^{3}$

\section{A DiNÂMICA DO ENVELHECIMENTO.}

\section{A VANGUARDA ENCHE OS MUSEUS}

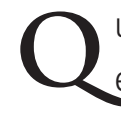
uaisquer que sejam os efeitos que possam produzir a consciência histórica e, mais especificamente, a profissionalização histórico-científica da memória, em nossa civilização moderna, eles certamente não resultaram em perda de vitalidade cultural. A relação que Nietzsche supunha existir entre ânsia de presentificação do passado e relutância de se criar o novo não existe. Caso Nietzsche estivesse vivo hoje, ele se espantaria com que intensidade persiste em nossa civilização a presentificação historista do passado sem que se perca sua dinâmica de inovação e, assim, sua aptidão para o futuro. De fato, "os museus estão em alta" e aquelas que na cultura alemã se denominam "ciências do espírito" - ou seja, as ciências histórico-culturais que se dedicam academicamente ao processo de musealização - sofreram, para Jürgen Mittelstrass (2005: 35ss), uma "perda de reputação" devido a seu envolvimento na "rebarbarização de um mundo que coloca seus valores num museu".

Todavia, bastam os aspectos financeiros da questão para colocar em dúvida a descrição nietzschiana das circunstâncias. Museus são caros e muito raramente autossustentáveis; eles exigem subvenção constante através de patrocinadores privados e organismos de fi- 
nanciamento público. Independentemente da dívida crescente das finanças públicas, nenhum partido político ousaria acabar com o financiamento aos museus. De fato houve certa vez um ataque aos museus, qual seja, na forma de uma atitude cultivada por artistas de vanguarda, e que, por sua vez, foi historicizada há muito tempo - Marinetti, por exemplo, com seu famoso e famigerado apelo a que se libertasse a Itália dos "inúmeros museus" que cobriam o país "como incontáveis cemitérios" impedindo o advento do futuro artístico. ${ }^{4}$ Ao invés disso, e na medida em que incontestavelmente forjou uma nova era, o futurismo artístico acelerou o processo de musealização. Isso aconteceria, escreveu Hans Tietze, um dos mestres de Ernst Gombrich, quando por meio de inovações envelhecem as inovações de ontem. 0 prazo de validade de uma inovação de vanguarda encolheria para apenas alguns meses, de tal forma que as obras do "jovem gênio" se tornariam antiquadas antes mesmo de sua tinta secar. Elas seriam levadas "para o museu sem um estágio intermediário" (Tietze, 1925: 60). Cresce, hoje, a demanda por locais de exposição para a arte de ontem que pretendia ser o amanhã. 0 interesse manifestado pelas massas crescentes de frequentadores de museus e a hesitante disposição da política em satisfazer tal demanda poderiam ser interpretados como uma negação do futuro, mas - diferentemente do que supunha Mittelstrass - justamente o museu se torna um espaço de demonstração da ilimitada satisfação político-cultural no trato das consequências da dinâmica de inovação cultural. Ainda não foi superada a análise do acima mencionado Ernst Gombrich sobre a complementaridade entre progresso e envelhecimento (Cf. Lübbe, 2004b: 99-113), a qual também determina a historicização da arte. Por boas razões Gombrich se baseia, quanto a isso, no conhecido livro de Popper (1980) sobre o historicismo.

A relação de complementaridade entre a dinâmica de inovação e historicização não se aplica apenas à arte, mas vale para a totalidade da civilização moderna - inclusive as ciências e a tecnologia. Mesmo os consumidores de automóveis de luxo que gostariam de sempre poder buscar na fábrica o modelo mais recente podem testemunhar ali mesmo, num museu do automóvel, esta complementaridade entre dinâmica de inovação e dinâmica de envelhecimento. Tornou-se famosa a declaração de um industrial durante as festividades de um museu de mineração em Bochum, de que "o museu da mineração está em expansão, mas a mineração está encolhendo", e que habilmente resumiu o processo de transformação da economia na região do Ruhr.

Com as ciências acontece algo análogo. A historiografia das ciências se expande complementarmente à dinâmica da pesquisa. Além do mais, foi como historiadores da matemática que matemáticos famosos mantiveram-se conhecidos em sua velhice. No contexto de evolução acelerada de nossa civilização, as técnicas, os métodos e os interesses de pesquisa da presentificação profissional do passado estão sujeitos a uma transformação dinâmica. As 
ciências históricas tornam-se, elas próprias, históricas. Surge atualmente uma arte de exposição museal do passado à qual os próprios museus têm destinado espaços de preservação. Os resultados das incompreensões históricas da preservação de monumentos de ontem tornam-se eles próprios alvos de preservação, etc.

\section{ArouiVAmento E ESQUECIMENTO ORgANIZADO}

P oder-se-ia prosseguir indefinidamente com as ilustrações dessas relações entre a acelerada evolução civilizacional e a historicização de suas relíquias. Junto da preservação de monumentos e da musealização poderia ser ainda evocada a instituição do arquivo. É sabido que processos de modernização são, entre outras coisas, processos de expansão social e regional de nossas dependências mútuas - informacionais e institucionais, econômicas e jurídicas. A quantidade de instâncias que estão interativamente conectadas umas às outras está aumentando dramaticamente. Isso se reflete na enxurrada de manuais de direito internacional que prescrevem as regras de tal interação. Ao mesmo tempo, o número de possibilidades de interação aumenta ao quadrado do número de instâncias que se tornaram dependentes umas das outras. Isso se manifesta por meio de cartas, atas e seus modernos equivalentes eletrônicos, e os resultados desses processos concluídos terminam, eventualmente, no arquivo. Com que finalidade? Em contraste com os arquivos pré-modernos, o material definitivamente arquivado já perdeu todo significado prático e principalmente jurídico. 0 propósito dos arquivos, que se expandem como nunca antes na história, não é outro senão o de garantir uma base documental para a auto-historicização da nossa civilização. Tal como a arquitetura dos museus adquiriu um significado crescente no urbanismo moderno, também a arquitetura dos arquivos adquiriu importância cultural - e até mesmo política, como ficou impressionantemente demonstrado no XI Congresso Internacional de Arquivistas em Paris, ocasião em que 0 presidente francês comemorou a recente construção de prédios de bibliotecas e arquivos na capital francesa (De Roux, 1988: 1, 17).

A referência aos arquivos nos dá, porém, ao mesmo tempo, ensejo de lembrar que no contexto do historismo especificamente moderno o esquecimento também desempenha seu papel. A tradição moral está bem familiarizada com este topos: a fim de lembrar-se de forma confiável das coisas relevantes temos de esquecer as trivialidades de forma igualmente confiável, o que no arquivo moderno é possibilitado pela assim chamada "eliminação", isto é, a responsabilidade última sobre aquilo que para os futuros interesses pelo passado será a parte irrelevante dos documentos antigos, e que assim acabará na picotadora de papel. 0 leigo se espanta com a extensão do material condenado ao definitivo esquecimento por meio 
da eliminação: hoje em dia, em regra mais de 90\% deste material é destruído, e, dependendo do conteúdo da informação arquivada, apenas $3 \%$ ou menos do material original é permanentemente arquivado. ${ }^{5}$

Relevante do ponto de vista de uma teoria da historicização é a questão de como 0 ato de eliminação diferencia o que é relevante do ponto de vista da memória daquilo que precisa ser esquecido. 0 critério é o interesse presumido das gerações futuras na historicização daquele passado que o nosso presente brevemente há de se tornar. Poder-se-ia chamar de "precepção" este ato de estimar da forma mais segura possivvel os futuros interesses de presentificação do passado. ${ }^{6}$ Isso só é possível caso existam interesses culturais dotados de uma certa constância antropológica. Também a cultura da memória, por conseguinte, em última análise se baseia em tais constantes.

Do ponto de vista prático e portanto cultural, à avaliação adequada da crescente importância de que goza a memória historicizante na civilização moderna, pertence também a consciência de que, para a grande maioria das atividades inovadoras que impulsionam a evolução da nossa civilização, as memórias não desempenham papel algum. Fortes interesses de presentificação do passado teriam um efeito perturbador ali onde o esquecimento do passado é considerado uma virtude. Isso vale para extensas áreas de pesquisa e desenvolvimento. Não foi sem razão que Harald Weinrich (2001: 290-296) concluiu seu já citado livro Lete com um "Epílogo sobre o esquecimento na ciência". "Tudo o que foi publicado há mais de cinco anos - forget it" - eis uma regra óbvia no contexto de inúmeros projetos de pesquisa e de desenvolvimento. Ao uso da expressão informal "forget it" por Weinrich não corresponde qualquer intenção irônica.

Daí advém uma consequência importante: o significado do historismo moderno em sua complementaridade estrutural com a dinâmica evolutiva da civilização não é o de aprender com o passado para possibilitar a ação no futuro. Esta é também a quintessência da famosa intuição de Reinhart Koselleck quanto à "desintegração", na virada dos séculos XVIII-XIX, do topos "Historia magistra vitae" enquanto narrativa-padrão significativa do dramático abandono feito pelo historismo da tarefa de aplicar as lições do passado para o bem do futuro (Koselleck, 1967: 196-219).

\section{HiSTORICISMO INESQUECÍVEL E POLÍTICAS DA MEMÓRIA MAIS ADEQUADAS}

s evidências mais fortes para a tese de que o sentido prático da presentificação cien-
tífico-historista do passado não é mais a obtenção de ensinamentos relevantes para o agir, portanto orientados para o futuro, são as consequências da recusa desta ideia. 0 filósofo 
Karl R. Popper deu a esta recusa o nome de "historicismo" ("Historizismus"). Ele estava se referindo à pretensão, ideologicamente concretizada no século $X X$, de se superar todas as tradicionais histórias cujo objetivo era oferecer lições e assim descobrir as leis do curso total da história - a saber, a "lei natural" do seu "movimento", como Karl Marx (1959: 7) as designou literalmente. Ligado à ideia complementar de que somente graças ao pertencimento à derradeira classe social resultante do desenvolvimento da luta de classes seria possível entender a regularidade desse processo, este "historicismo" tornou-se a autolegitimação insuperável na batalha final histórico-universal desta classe derradeira. Popper dedicou seu livro sobre o historicismo às vítimas desta batalha final. Entre os destinatários dessa dedicatória Popper incluiu ainda as vítimas da teoria da luta de raças na história, que, embora fosse incomparavelmente menos elaborada, também tinha se munido com a insuperável legitimação de que seria necessário pertencer à raça vitoriosa e superior para estar apto ao entendimento da verdade de seu papel de liderança histórico-universal (cf. Lübbe, 2003: 137-154).

Como dissemos acima, Karl R. Popper dedicou seu livro às vítimas da política, legitimada no historicismo, dos sistemas totalitários. Coloca-se igualmente a questão de saber se ao sentido do historismo em sua afiliação à civilização moderna não corresponderia o esforço de evitar o esquecimento das vítimas da perversão totalitária dessa mesma civilização. Por razões que dispensam explicação, é bastante difundida - especialmente na Alemanha - a boa opinião de que a lembrança histórica serve especialmente a este fim. Isso tem lá sua plausibilidade, no entanto é incorreto. A presença duradoura dos horrores da dominação totalitária não é causada pela historicização desta dominação. A verdadeira razão radica numa força muito maior ainda - o poder da memória coletiva, com a qual a consciência histórica moderna, enquanto instância moderadora e disciplinadora, sempre se relaciona intimamente. Isso vale inclusive para a lembrança de histórias sobre coisas que se tornaram célebres, e ainda o velho Kant considerava a Revolução Francesa como um acontecimento impossível de ser esquecido. ${ }^{7}$ Certas consequências desta revolução evidentemente precipitaram Kant num estado de "tristeza" que jamais se desfaz num salutar esquecimento - aquela tristeza, precisamente, que Kant designava "sublime", porque sua origem estaria naquelas "crueldades" que os seres humanos praticam justamente ao perseguir os "objetivos tidos como importantes e grandiosos" para si (Kant, 1920: 348). Atualmente isso pode ser lido como um prelúdio da posterior percepção quanto às origens do terrorismo político moderno, o qual se baseia na vontade ideocrática de realização do - afinal conhecido - sentido último da história.

Ou seja: a historicização do terror, tanto a mais antiga como a atual, seria interpretada erradamente caso fosse tomada como um meio de não-esquecimento do terror. Isso fica evidente quando nos damos conta de que somente as respostas politicamente viáveis 
àqueles regimes de terror fracassados é que possibilitaram a sua historicização. No caso alemão, significa: a resposta adequada à ditadura do Partido Nazista foi a segunda democracia alemã - isso tanto no processo de refundação das instituições políticas quanto nas histórias individuais de vida dos alemães (cf. Lübbe, 2007a). 0 impacto destes eventos inesquecíveis ao longo de gerações e suas duradouras consequências levaram, nesse meio tempo, à imediata historicização do nacional-socialismo, fazendo do Terceiro Reich o período mais bem investigado da história alemã. Nesse sentido é impossível afirmar que o nacional-socialismo tenha sido suprimido da memória dos alemães.

O que evidentemente não significa que não houve indivíduos, e inclusive suas filiações institucionais e informais, que tenham buscado e se beneficiado da crença em histórias inventadas a respeito de si mesmos, e conhecem-se casos em que tudo foi descoberto. No mundo acadêmico houve o caso espetacular de um conhecido reitor progressista que se libertara de seu passado de oficial da SS alterando sua identidade, até que sua segunda e brilhante carreira desmoronou quando contemporâneos revelaram seu passado até então suprimido. Mas este não foi um caso de representificação de um passado por meio da investigação histórica, e sim um desmascaramento por meio de reconhecimento casual como consequência real de um passado que supostamente nunca existiu, e o meio mais adequado para lidar com esse tipo de passado não foi a sua historicização, mas uma ação disciplinar. É claro que o significado histórico deste caso fez dele também, consequentente, um objeto de investigação em história do presente (Cf. Lübbe, 1997a: 182-206, 334-336).

0 sentido forense de se revelar passados encobertos que produziriam consequências jurídicas, bem como o sentido terapêutico da representificação analítica de passados reprimidos não é o mesmo da presentificação historiográfica do passado. Seria um mal-entendido grosseiro afirmar que as ciências históricas poderiam servir à práxis política e de comunicação moral da mesma forma que as ciências teóricas, sobretudo as ciências naturais, servem à técnica. ${ }^{8}$ A semântica da palavra "práxis" se relaciona a um tipo de interesse que de forma alguma nos leva a pesquisar as tradições funerárias no museu de Kassel, e menos ainda a amealhar lucros às custas de estudos sobre coleções históricas de armas num arsenal. Por que razão, no último dos fragmentos a que deu título em sua famosa crítica da razão pura, Kant anunciou uma "História da razão pura" a ser escrita "futuramente", é uma questão cuja resposta contribui para a compreensão dos fundamentos da progressiva auto-historicização da filosofia do século XIX, mas que simplesmente não o é para o avanço da pesquisa em historiografia da filosofia. ${ }^{9}$ Ademais, a evidência da irrelevância prática de tais interesses históricos nem de longe é fruto dos exemplos aqui evocados. Ao lidar com os cenários investidos de grande importância política nacional do monumento de Kyffhäuser, com suas relíquias do império de 
Bismarck, da República de Weimar e até mesmo da antiga Alemanha Oriental, não somos levados a assumir um engajamento político nem nos tornamos mais competentes politicamente. E mesmo no caso histórica e politicamente importante do arquivo especial erigido para abrigar as atas da polícia secreta da Alemanha Oriental, em última análise não encontramos, depois de expirado o prazo de prescrição dos crimes ali documentados, nada além das possibilidades que permitem o estabelecimento e a descrição do que realmente aconteceu..$^{10}$

Ainda temos na memória os debates, ocorridos há quatro décadas, sobre se a "história" enquanto disciplina escolar deveria ser abolida ou reformulada, quando os apologistas desta disciplina tentaram ressaltar sua relevância prática alegando que a ciência histórica e as aulas de história ofereciam "possibilidades de identificação". Realmente, é certo que aquele que deseje saber quem uma determinada pessoa é ou foi tem que recorrer aos biógrafos entre nossos historiadores. "A história representa o homem" - assim formulou o fenomenólogo das histórias Wilhelm Schapp antes do advento da era feminista (Schapp, 2007: 116). A função de presentificação de identidade da historiografia também se aplica a instituições e coletividades. Mas com isso não se oferecem ao público possibilidades de criação de uma identidade. 0 que uma pessoa foi - uma vez que aconteceu de uma determinada forma e não de qualquer outra - permanece algo inalterável, independente da dinâmica de nossos próprios interesses na presentificação de individualidades em sua inexorável inefabilidade, como as chamou Goethe. As partes em conflito no Kulturkampfnaturalmente tinham uma imagem diferente de Lutero, e faz diferença se os livros de história esclarecem para as crianças alemãs a fundação do Império em 1871, ou, como se pretendia em 1968, a visão de futuro da Comuna de Paris. Mas tais diferenças não provam que o que realmente aconteceu deva ser entendido como uma mera função de interesses cognitivos práticos e, portanto, como um "construto". Ao contrário, elas significam que uma troca de imagens, por vezes abrupta, nas molduras das assim chamadas políticas da memória não acontece de forma independente das nossas respectivas situações contingentes de vida. Contudo, e excetuadas as limitações dogmáticas ou mesmo totalitárias impostas por tais políticas, tal troca permanece inteiramente historicizável, e a compatibilidade das respectivas imagens é obtida ao menos enquanto sua definição se mantém submissa à norma historista, atenta às regras metódicas da profissão de se dizer o quê e como realmente aconteceu. Significa, para recorrer a um caso exemplar: Heinrich Treitschke, nascido na Saxônia e prussiano por opção, foi o mais dinâmico dos historiadores que se aliaram à solução bismarckiana na formação do Império Alemão ao invés da tradição dos católicos e dos nacionalistas românticos, partidários da incorporação da Áustria. No entanto, a historiografia do século XIX de Treitschke ainda é uma leitura cativante - por exemplo, para a compreensão da outrora grande popularidade de Napoleão, não só na Alemanha, e em sua descrição da modernidade político-jurídica e administrativa das novas regiões prussianas a oeste do Reno. 


\section{POR QUE NOS INTERESSA AQUILO QUE SÓ PODE SER EXPLICADO HISTORICAMENTE}

P erguntamo-nos aqui sobre as causas do fato de que justamente nos contextos de vida de uma civilização técnico-científica, que se tornou moderna e altamente dinâmica, o interesse histórico atinja um nível sem precedentes - literalmente "sem precedentes" quando medido à luz do esforço, que aqui esboçamos, representado pela musealização, pela patrimonialização, pela preocupação com os arquivos e outras formas contemporâneas de presentificação profissional do passado. E se, não obstante, as políticas da memória recentes ou recém elaboradas não estiveram submetidas sobretudo a um interesse prático - a que outro tipo de interesse então? Na busca por uma resposta adequada chega-se, assim me parece, à consideração sobre a já mencionada complementaridade entre envelhecimento e dinâmica da inovação. Complementarmente à taxa de inovação aumenta o montante de relíquias históricas e assim, ao mesmo tempo, a quantidade dos bens culturais que para se manterem compreensíveis ou voltarem a ser compreendidos demandam uma explicação especial do ponto de vista metodológico - ou seja, uma explicação histórica. Em vez de recorrer a exemplos da história das ciências culturais históricas para demonstar a força de elucidação das explicações históricas, vale a pena evocar os primórdios das ciências naturais históricas. Isso vale a pena sobretudo no contexto da história das ciências na Alemanha porque uma de suas especificidades, nos primórdios do historismo, e que só pode ser explicada historicamente, foi a de negar totalmente a historicidade daquela que desde Plínio o Velho era denominada Historia naturalis, incluindo a sua transfiguração moderna em ciências naturais históricas (por exemplo a geologia e especialmente a palenteologia e a cosmologia). ${ }^{11}$

Ninguém menos que Johann Gustav Droysen acreditava que "o momento temporal" seria "secundário" e se desmancharia "em círculos e períodos idênticos que se repetem". Por sua vez, a "história, num sentido pleno", seria unicamente "a do universo moral (sittlichen Kosmos)", a história "do mundo humano" (Droysen, 1937: 11-13). Uma explicação minimamente satisfatória deste mal-entendido a partir da perspectiva da história da ciência resultaria muito complexa. Uma parte desta explicação teria de envolver as consequências do fato histórico-científico de que as modernas disciplinas dedicadas à história da natureza se estabeleceram academicamente na Prússia depois da Inglaterra ou da França, e mesmo depois de regiões do sudoeste alemão como a Baviera e a Áustria. De uma forma ou de outra, as consequências se estendem longamente - chegando até Hans-Georg Gadamer. A tese da unidade do conceito de história abrangendo, de um lado, as ciências culturais históricas, e, de outro, as ciências naturais históricas, foi comentada criticamente por ele quando perguntou 
em que afinal consistiria "uma conexão entre a história do universo com a história que os seres humanos experimentam entre si e conjuntamente" (Gadamer, 1995: 208). Aprende-se porém em qualquer visita a um museu da mineração, da mesma forma que em toda visita a gabinetes barrocos de curiosidades, nos quais, entre outras coisas, se colecionavam aquelas antiguidades descontextualizadas - e por esta mesma razão tidas como curiosas - que hoje tentamos tornar compreensíveis para nós mesmos enquanto relíquias de uma evolução. Justamente por essa razão nós as explicamos historicamente. Por exemplo: restos de esqueletos de mamíferos marinhos, e que o tempo tornou destituídos de função, são explicados por meio de uma pré-história paleontológica desta espécie antes de sua posterior adaptação, produzida por contingências, às condições de uma permanência duradoura no mar.

Nós explicamos historicamente aquilo que, ao invés de acontecer em conformidade com expectativas seguras, processos ou regularidades conhecidas, ocorre em consequência de eventos que intervêm de forma contingente, ou graças a efeitos colaterais imprevisíveis. Por exemplo o fato demográfico, repleto de consequências inesperadas, de que Malthus estava errado e que o bem-estar constante, ao invés elevar de forma catastrófica as taxas de reprodução populacional, na verdade as fez declinar ${ }^{12}$ - entrementes, até mesmo em dimensões catastróficas.

No geral a historiografia se torna um recurso cultural eficaz e fundamental enquanto um meio de experiência de contingências - seja na perspectiva da história natural, da história de gênero ou da história cultural. ${ }^{13}$ Hans Blumenberg compreendeu isso de forma impressionante, resumindo os aspectos naturais, técnicos e culturais de uma experiência de contingência historicisticamente intensificada - por exemplo, em sua análise da transformação irreversível que a cosmonáutica produz em nossa experiência do mundo e da existência. A notarmos bem, ver a Terra de fora, da Lua, não implica apenas uma confirmação do acerto do modelo de Copérnico por meio da observação. Tal observação se combina com um deslocamento simultâneo, existencial - ou seja: na esfera do mundo da vida - da Terra para uma situação de inevitável centralidade. E na presentificação historicizada das condições científicas, técnicas e cosmovisionais deste efeito, percebe-se a contingência de nossa condição com incomparável intensidade. A partir do conhecimento histórico percebe-se que também o assim chamado Cosmos - ele próprio algo historicamente explicável - é uma referência histórica, e é mister recorrer às palavras do poeta para descrever a emoção produzida pela visão histórica de nossa situação no mundo: "triste e magnífica" (Cf. Blumenberg, 1975: 782ss).

Da perspectiva da história cultural da ciência, significa: a eficaz inclinação cultural alemã, herdada do século XIX, de se contrastar as ciências naturais e as ciências culturais, se reconsolida em uma consciência bem mais apropriada à nossa moderna experiência do 
mundo - a da unidade de todas as ciências históricas. Essa consciência da historicidade do nosso lugar natural e cultural tem certamente a sua pré-história, que remonta ao século XIXinconfundivelmente manifesta, por exemplo, nos edifícios igualmente relevantes, do ponto de vista arquitetônico, dos palácios do Museu Histórico-Natural e do Museu Histórico-Cultural, complementarmente dispostos um em frente ao outro na Ringstrasse de Viena. Ou na duplicidade do monumento aos irmãos Humboldt na entrada da Universidade de Berlim, com o historiador da natureza Alexander, de um lado, e o historiador da cultura Wilhelm do outro.

A dinâmica de nossa civilização é tal que seu poder de gerar passado leva, como nunca antes na história, a uma incômoda atualidade do que é pretérito, e ao mesmo tempo nos aproxima da diferença contingencial daqueles que são diferentes de nós. Em consequência da modernização cresce o incômodo com as diferenças e as incompreensões que, por sua vez, só podem ser explicadas historicamente. ${ }^{14}$ Cabe ainda dizer, por fim, que as experiências temporais modernas, marcadas pela tendência à auto-historicização de nossa civilização, não têm de se reduzir ao retorno a experiências de efemeridade culturalmente dominantes. Juntamente com a experiência crescentemente incômoda, na verdade tipicamente moderna, de uma aceleração dos processos de envelhecimento, ao mesmo tempo tornamo-nos cada vez mais conscientes daqueles requisitos culturais e naturais que se caracterizam por sua grande resistência ao envelhecimento - o "clássico", como por exemplo no caráter especificamente moderno e temporal deste conceito (Cf. Lübbe, 2007b: 17-36). Os compromissos que deveriam acelerar a dinâmica civilizacional, com seus inúmeros efeitos secundários, tornaram-se obsoletos. Na teoria da ciência, isso se reflete no já convencional abandono do conceito de progresso pelo de inovação.

0 que finalmente se depreende é que, em contraste com a cultura, a natureza parece-nos ser a entidade marcada por uma duração relativamente mais lenta. Os mais citados teóricos das ciências culturais, de Droysen a Gadamer, extraíram daí a conclusão de que as ciências naturais históricas seriam irrelevantes do ponto de vista histórico-cultural. Eles não perceberam que, nesse meio tempo, graças à comparação entre natureza e cultura sob o ponto de vista de sua historicidade, a nossa própria cultura se transformou.

\section{Notas}

1 NT: Uma vez que Lübbe distingue "historismo" (Historismus) de "historicismo" (Historizismus), foi necessário manter aqui tal distinção, o que parece fazer pouco sentido em português. O leitor deve estar atento para o fato de que Lübbe emprega o segundo conceito na mesma acepção de Karl Popper. Como se verá adiante, nessa perspectiva "historicismo" designa toda teoria abrangente do processo histórico, e que tenha a pretensão de antever o curso dos desenvolvimentos futuros (Popper via em Hegel, Comte e Marx exemplos clássicos 
de "historicismo"). 0 conceito de "historismo", por oposição, compreende a longa tradição do pensamento histórico europeu que dá particular ênfase à historicidade, à singularidade e ao papel da contingência. A respeito, ver Lübbe (1977: 120).

2 Sobre a "reavaliação do historismo" na preservação patrimonial, ver Walter Frodel (Frodel, 1974: 101).

3 Como um prelúdio a esse respeito, ver Gadamer (1996). "Ninguém", resume ele, teria "reconhecido com maior clareza que Nietzsche [...] a consequência" da consciência "de nossa historicidade [...] sobre a conformação do mundo atual" (Gadamer, 1996: 11).

4 Segundo a tradução alemã do conteúdo do primeiro Manifesto Futurista de 1909 (Hess, 1984: 72).

5 Essencial sobre a questão da "eliminação" (Kassation) é o livro de Eckhart Franz (Franz, 1990: 81).

6 Ver a respeito meu ensaio (Lübbe, 1997b: 23-50). Especificamente sobre o conceito de "precepção", cf. Lübbe (1997b: 25-29).

7 Assim se expressa Kant em seu escrito tardio sobre "O conflito das faculdades" (Kant, 1922: 398).

8 É a opinião de Habermas (1975: 291-302) em sua famosa conferência inaugural de 1965.

9 Certa vez, há mais de meio século, tentei responder esta exemplar questão histórico-filosófica (Lübbe, 1962: 204-229).

10 Daí decorre, em todo o caso, a questão relativa à política de arquivos: se, e por que razões, se deveria manter o estatuto especial dos arquivos do Ministério de Segurança do Estado (Stasi) da Alemanha Oriental. Esta questão também foi um dos temas do colóquio realizado em Berlim entre 27 e 29/11/2002, documentado por Dagmar Unverhau (Unverhau, 2003).

11 Para uma história deste mal-entendido histórico-científico, ver Lübbe (2006: 169-185).

12 Explicado historicamente por Herwig Birg (Birg, 2001). Uma síntese ultracurta da explicação histórica em questão é dada na seção "O efêmero efeito-Malthus: efeitos produtivos do bem-estar e os inícios da política demográfica" de meu ensaio (Lübbe, 2008: 22-25).

13 É o que demonstra, através de inúmeros aspectos da cultura histórica moderna, o último volume da longa série de publicações do grupo de trabalho Poética e Hermenêutica (Graevenitz, Marquard, Christen, 1998).

14 A teoria analítica da operação "explicação histórica" constituía a quintessência de meu antigo livro Conceito de história e interesse histórico (Lübbe, 1977). A segunda edição dispõe de uma nova e extensa introdução (Lübbe, 2012: 9-36) que descreve as mais recentes concepções, e também as auto-incompreensões, das tendências à auto-historicização de nossa época.

\section{REFERÊNCIAS BIBLIOGRÁFICAS}

BIRG, Herwig. Die demographische Zeitwende. Der Bevölkerungsrückgang in Deutschland und Europa. München: C. H. Beck, 2001.

BLUMENBERG, Hans. Reflexive Teleskopie und geotrope Astronautik. In: . Die Genesis der kopernikanischen Welt. Frankfurt am Main: Suhrkamp, 1975. 
DE ROUX, Emmanuel. Le Onzième Congrès International des Archives. La mémoire du futur. Le Monde, 26/08/1988.

DROYSEN, Johann Gustav. Historik. Enzyklopädie und Methodologie der Geschichte. München: Oldenbourg, 1937.

FRANZ, Eckhart. Einführung in die Archivkunde. Darmstadt:Wissenschaftliche Buchgesellschaft, 1990.

FRODEL, Walter. Max Dvořáks "Katechismus der Denkmalpflege". Österreichische Zeitschrift für Kunst und Denkmalpflege, v. 28, n. 3, pp. 74-105, 1974.

GADAMER, Hans-Georg. Geschichte des Universums und Geschichtlichkeit des Menschen. In: Gesammelte Werke, Band 10. Tübingen: Mohr Siebeck, 1995, p. 206-222.

Präludium. Erinnerung und Geschichte. In: BORCHMEYER, Dieter (Hrsg.) "Vom Nutzen und Nachteil der Historie für das Leben". Nietzsche und die Erinnerung in der Moderne. Frankfurt am Main: Suhrkamp, 1996, p. 11-14.

GRAEVENITZ, Gerhard von; MARQUARD, Odo; CHRISTEN, Matthias (Hrsg.) Kontingenz. Poetik und Hermeneutik Band XVII. München: Wilhelm Fink, 1998.

HABERMAS, Jürgen. Conhecimento e interesse. In: LOPARIĆ, Željko; ARANTES, Otília B. Fiori (Eds.) Textos escolhidos. Coleção Os Pensadores, vol. 48. São Paulo: Abril, 1975, p. 291-302.

HESS, Walter. Dokumente zum Verständnis der modernen Malarei. Reinbeck bei Hamburg: Rowohlt, 1984, p. 71-72.

KANT, Immanuel. Kritik der Urteilkraft. In: .Werke. Band V (ed. Ernst Cassirer). Berlin: Bruno Cassirer, 1920. 1922.

Der Streit der Fakultäten (1798). In: Werke. Band VII (ed. Ernst Cassirer). Berlin: Bruno Cassirer,

KLOTZ, Heinrich. Moderne und Postmoderne. Architektur der Gegenwart 1960-1980. Braunschweig/Wiesbaden: Fried. Vieweg \& Sohn, 1987.

KOSELLECK, Reinhart. Historia magistra vitae. Über die Auflösung des Topos im Horizont neuzeitlich bewegter Geschichte. In: BRAUN, Hermann; RIEDL, Manfred (Hrsg.) Natur und Geschichte. Karl Löwith zum 70. Geburtstag. Stuttgart/Berlin/Köln/Mainz: Kohlhammer, 1967, p. 196-219.

LÜBBE, Hermann. Philosophiegeschichte als Philosophie. Zu Kants Philosophiegeschichtsphilosophie. In: OEHLER, Klaus; SCHAEFFLER, Richard (Hrsg.) Einsichten. Gerhard Krüger zum 60. Geburtstag. Frankfurt am Main: Klostermann, 1962, p. 204-229.

Geschichtsbegriff und Geschichtsinteresse. Basel: Schwabe, 1977.

Deutschland nach dem Nationalsozialismus 1945-1990. Zum politischen und akademischen Kontext des Falles Schneider alias Schwerte. In: KÖNIG, Helmut; KUHLMANN, Wolfgang; SCHWABE, Klaus (Hrsg.) Vertuschte Vergangenheit. Der Fall Schwerte und die NS-Vergangenheit der deutschen Hochschulen. München: C. H. Beck, 1997a, p. 182-206.

Zeit-Erfahrungen. Sieben Begriffe zur Beschreibung moderner Zivilisationsdynamik. In: Modernisierung und Folgelasten. Trend kultureller und politischer Evolution. Berlin/Heidelberg/New York: Springer, 1997b, p. 23-50. 
Politischer Avangardismus oder Fortschritt und Terror. In: Im Zug der Zeit. Verkürzter Aufenthalt in der Gegenwart. Berlin/Heidelberg/New York: Springer, 2003, p. 137-154.

Denkmale in einer dynamischen Zivilisation. In: Modernisierungsgewinner. Religion, Geschichtssinn, Direkte Demokratie und Moral. München: Wilhelm Fink, 2004a, p. 114-128.

Die Kunst und der Fortschritt. In: Modernisierungsgewinner. Religion, Geschichtssinn, Direkte Demokratie und Moral. München: Wilhelm Fink, 2004b, p. 99-113.

Die Einheit von Naturgeschichte und Kulturgeschichte. Zur Korrektur eines deutschen wissenschaftstheoretischen Vorurteils. In: Philosophie in Geschichten. Über intelektuelle Affirmationen und Negationen in Deutschland. München: Wilhelm Fink, 2006, p. 169-185.

Vom Parteigenossen zum Bundesbürger. Über beschwiegene und historisierte Vergangenheiten. München: Wilhelm Fink, 2007a.

Zivilisationsdynamik. Das Alte, das Neue und die Wissenschaften. In: KODALLE, Klaus (Hrsg.) Geisteswissenschaften - im Gegenwind des Zeitgeistes? Zum Abschluss des Historischen Wörterbuchs der Philosophie. Akademie der Wissenschaften und der Literatur. Abhandlungen der Geistes- und sozialwissenschaftlichen Klasse. Jahrgang 2007. Mainz/Stuttgart: Franz Steiner, 2007b, p. 17-36.

Demographie wissenschaftskulturell, religiös und politisch. Historischer und aktuelle Aspekte. In: WERZ, Nikolaus (Hrsg.) Demographischer Wandel. Veröffentlichungen der Deutschen Gesellschaft für Politikwissenschaft. Band 25. Baden-Baden: Nomos, 2008, p. 13-31.

Einleitung zur Neuauflage. In: Geschichtsbegriff und Geschichtsinteresse. Basel: Schwabe, 2012, p. 9-36.

. Zivilisationsdynamik. Ernüchterter Fortschritt politisch und kulturell. Basel: Schwabe, 2014.

MARX, Karl. Das Kapital. Kritik der politischen Ökonomie. Erster Band. Vorwort zur ersten Auflage (1867). Berlin, 1959, p. 5-9.

MITTELSTRASS, Jürgen. Europa erfinden. Über die europäische Idee, die europäische Kultur und die Geisteswissenschaften. Merkur. Deutsche Zeitschrift für europäisches Denken, v. 59, n. 1, p. 28-37, 2005.

NIETZSCHE, Friedrich. Segunda consideração intempestiva. Da utilidade e desvantagem da história para a vida. Rio de Janeiro: Relume Dumará, 2003.

. Unzeitgemässe Betrachtungen. Erstes Stück: David Strauss. Der Bekenner und Schriftsteller. In:

Sämtliche Werke. Kritische Studien-Ausgabe in 15 Bänden. Herausgegeben von Giorgio Colli und Mazzino Montinari. Band 1. München: DTV, 1980, pp. 175-204.

POPPER, Karl. A miséria do historicismo. São Paulo: Cultrix/Edusp, 1980.

SCHAPP, Wilhelm. Envolvido em histórias. Porto Alegre: Sérgio Antonio Fabris, 2007.

TIETZE, Hans. Lebendige Kunstwissenschaft. Zur Krise der Kunst und der Kunstgeschichte. Wien: Krystall, 1925.

UNVERHAU, Dagmar (Hrsg.) Hatte "Janus" eine Chance? Das Ende der DDR und die Sicherung einer Zukunft der Vergangenheit. Münster: LIT Verlag, 2003.

WEINRICH, Heinrich. Lete. Arte e crítica do esquecimento. Rio de Janeiro: Civilização Brasileira, 2001. 